\title{
CALCÁRIO E ESCÓRIA DE SIDERURGIA AVALIADOS POR ANÁLISE FOLIAR, ACÚMULO, E EXPORTAÇÃO DE MACRONUTRIENTES EM CANA-DE-AÇÚCAR
}

\author{
Renato de Mello Prado ${ }^{1,4 *}$; Francisco Maximino Fernandes²; William Natale ${ }^{3}$ \\ ${ }^{1}$ Pós-Graduando em Produção Vegetal - UNESP/FCAV. \\ ${ }^{2}$ Depto. de Fitossanidade, Engenharia Rural e Solos - UNESP/FEIS, Av. Brasil 56 - CEP: 15385-000 - Ilha Solteira, \\ $S P$. \\ ${ }^{3}$ Depto. de Solos e Adubos - UNESP/FCAV, Via de Acesso Prof. Paulo Donato Castellane s/n ${ }^{\circ}$ - CEP: 14870-000 - \\ Jaboticabal, SP. \\ ${ }^{4}$ Bolsista FAPESP. \\ *Autor correspondente <rmprado@fcav.unesp.br>
}

RESUMO: A opção de uso de materiais corretivos alternativos como as escórias de siderurgia, pode influenciar na absorção de nutrientes pela planta e, consequentemente, na diagnose foliar, acúmulo e exportação de nutrientes. Com o objetivo de estudar o efeito da aplicação de doses de escória de siderurgia e de calcário na absorção de macronutrientes pela cana-de-açúcar (variedade SP80-1842), foi instalado em janeiro de 1998, em Ituverava-SP, um experimento de campo. Aplicou-se escória de siderurgia e calcário, em quatro doses equivalentes $0 ; 1,23 ; 2,52$ e 3,80 $\mathrm{t} \mathrm{ha}^{-1}$ de $\mathrm{CaCO}_{3}$, em um Latossolo Vermelho-Amarelo distrófico, em pré-plantio na cana-planta. Determinaram-se, além da produção de colmos, as concentrações de macronutrientes na folha +3 da cana-planta e da cana-soca (aos 120 dias após a emergência dos brotos) e na parte aérea da cana-soca (aos 345 dias após a emergência dos brotos). Os materiais corretivos e as doses não alteraram a absorção de macronutrientes pela cana-de-açúcar. Houve maior acúmulo e exportação de macronutrientes de acordo com as doses de ambos corretivos. A escória de siderurgia comportou-se de modo semelhante ao calcário na nutrição da cana-de-açúcar quanto aos macronutrientes.

Palavras-chave: Saccharum sp., resíduo siderúrgico, calagem, nutrição, extração

\section{LIME AND SLAG EVALUATED BY LEAF ANALYSIS, MACRONUTRIENT ACCUMULATION AND EXPORT OF SUGARCANE}

\begin{abstract}
Slag can be used as an alternative for lime as soil amendment, having influence on nutrient uptake by the plant and, as a result, on leaf analysis and nutrient accumulation. To study the effect of the application of increasing rates of slag and lime stone on the uptake of macronutrients by sugar cane (variety SP 80-1842) an experiment was installed under field conditions, in January 1998, at Ituverava-SP, Brazil. Slag and limestone were applied to the sugarcane crop at planting, in four rates: $0 ; 1.23 ; 2.52$ and $3.80 \mathrm{t} \mathrm{ha}^{-1}$ of $\mathrm{CaCO}_{3}$, using a Typic Haplorthox. In addition to the cane stalk production a verification was performed for the first and second ratoons (120 days and 345 after the emergence of the shoots, respectively). Macronutrient concentrations on the leaf +3 and in the aerial part of sugar cane for were analysed for the second cutting. Through leaf analysis data it was found that the corrective agents and rates did not modify the degree of absorption of macronutrients by the sugar cane. Slag had some effect on sugarcane evaluation, acting in a similar way in comparison to limestone, in relation to the nutrition of the plant.
\end{abstract}

Key words: Saccharum sp., slag, lime, nutrition, extraction

\section{INTRODUÇÃO}

A agroindústria sucroalcooleira constitui um dos setores do agronegócio mais importantes para a economia primária brasileira. O setor movimenta anualmente $\mathrm{R} \$ 12$ bilhões de reais. Considerando somente o Estado de São Paulo, a cadeia de produção de açúcar e álcool responde por $40 \%$ do emprego rural e $35 \%$ da renda agrícola (Carvalho, 1999). Um dos aspectos conhecidos e responsáveis pela alta produção da cana-de-açúcar é a adequada nutrição da cultura, tendo em vista a baixa fertilidade natural dos solos brasileiros.
A cultura canavieira está instalada em uma área de 4,9 milhão de hectares, consumindo-se 1,6 milhão de toneladas de fertilizantes, sendo a cultura na qual mais se aplica adubo por unidade de área (ANDA, 2000).

Nas áreas tropicais, sabe-se que, para que os fertilizantes aplicados tenham a máxima eficiência, tornase necessária a correção da acidez do solo, o que tem sido feito empregando-se os calcários. Entretanto, existem materiais corretivos alternativos, sendo o mais promissor a escória de siderurgia (Prado, 2000). As escórias apresentam o ânion silicato que corrige a acidez do solo, embora com ação mais lenta comparado ao calcário (Prado \& Fernandes, 2000). Apesar de estarem 
disponíveis no mercado brasileiro, têm sido pouco comercializadas para esse fim (Quaggio, 2000).

Para avaliar o potencial da escória de siderurgia, comparando-a ao calcário, para ser empregado na cultura da cana-de-açúcar, há necessidade de acompanhar os efeitos na nutrição da planta, uma vez que os materiais corretivos podem afetar a fertilidade do solo, a disponibilidade dos elementos e, conseqüentemente, a absorção e translocação de nutrientes.

São raros os trabalhos que têm sido desenvolvidos com cana-de-açúcar enfocando a exigência nutricional e a exportação de macronutrientes, especialmente nas variedades mais modernas, as quais sofreram significativa interferência genética através do melhoramento vegetal.

Em um dos primeiros trabalhos desenvolvidos em São Paulo, Catani et al. (1957) encontraram na canade-açúcar, variedade Co 419, as seguintes quantidades máximas de elementos, extraídos por toneladas de colmos: $1,32 \mathrm{~kg}$ de $\mathrm{N} ; 0,21 \mathrm{~kg}$ de $\mathrm{P}_{2} \mathrm{O}_{5} ; 1,31 \mathrm{~kg}$ de $\mathrm{K}_{2} \mathrm{O}$; $0,36 \mathrm{~kg}$ de $\mathrm{CaO} ; 0,32 \mathrm{~kg}$ de $\mathrm{MgO} ; 0,14 \mathrm{~kg}$ de S. Para a variedade CB 41-76, Orlando Filho et al. (1980) determinaram a seguinte ordem de extração de macronutrientes: $\mathrm{K}>\mathrm{N}>\mathrm{Ca}>\mathrm{Mg}>\mathrm{S}>\mathrm{P}$.

Objetivo do presente trabalho foi estudar o efeito da aplicação de doses de escória de siderurgia e calcário, na absorção dos macronutrientes pela cana-deaçúcar (variedade SP80-1842).

\section{MATERIAL E MÉTODOS}

O experimento foi realizado na área experimental da Fazenda Nossa Senhora Aparecida, no município de Ituverava (SP), localizado a $20^{\circ} 20^{\prime} 00^{\prime \prime}$ de latitude Sul, $47^{\circ} 47^{\prime} 20^{\prime \prime}$ de longitude Sul, cujo clima é mesotérmico com verão quente e úmido (Cwa), de acordo com o sistema Köppen. O solo é um Latossolo VermelhoAmarelo distrófico, com as seguintes características químicas: matéria orgânica $=24 \mathrm{~g} \mathrm{dm}^{-3} ; \mathrm{pH} \mathrm{em} \mathrm{CaCl}_{2} 0,01$ $\mathrm{mol} \mathrm{L}^{-1}(1: 2,5)=4,6 ;$ P-resina $=5 \mathrm{mg} \mathrm{dm}^{-3} ; \mathrm{K}=0,4 ; \mathrm{Ca}=$ 8,$0 ; \mathrm{Mg}=5,0 ; \mathrm{H}+\mathrm{Al}=38,0 \mathrm{mmol}_{\mathrm{c}} \mathrm{dm}^{-3}$ e saturação por bases $=26 \%$, avaliadas segundo os métodos descritos por Raij et al. (1987).

Utilizou-se a escória de siderurgia com as seguintes características químicas: $\mathrm{Cu}=0,4 ; \mathrm{Zn}=0,9 ; \mathrm{B}=$ 0,$3 ; \mathrm{Mn}=24,7 ; \mathrm{Fe}=261,8 \mathrm{~g} \mathrm{~kg}^{-1}$, analisado em extrato de

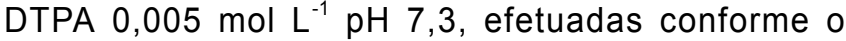
método descrito por Lindsay \& Norwell (1978), exceto o $B$ que foi pelo método da água quente (Bataglia \& Raij, 1990); $\mathrm{CaO}=252 \mathrm{~g} \mathrm{~kg}^{-1} ; \mathrm{MgO}=25 \mathrm{~g} \mathrm{~kg}^{-1} ; \mathrm{PN}=51,4$;

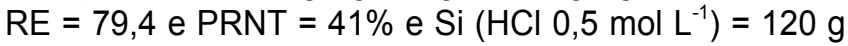
$\mathrm{kg}^{-1}$ (NIAES, 1987). O calcário utilizado foi o calcítico, com as seguintes características: $\mathrm{CaO}=372 \mathrm{~g} \mathrm{~kg}^{-1}$; $\mathrm{MgO}=$ $27 \mathrm{~g} \mathrm{~kg}^{-1} ; \mathrm{PN}=87,8 ; \mathrm{RE}=73,3$ e PRNT $=64 \%$. A escolha desse calcário deveu-se por apresentar teor de $\mathrm{MgO}$ semelhante ao da escória de siderurgia.
Os tratamentos, com quatro repetições, foram dispostos em blocos casualizados, em esquema fatorial 2x4 (2 fontes de corretivo e quatro níveis de correção), totalizando 32 unidades experimentais. As doses de corretivo foram aplicadas com o objetivo de elevar a saturação por bases aos valores de $50 \%, 75 \%$ e $100 \%$, correspondendo, respectivamente, em equivalente $\mathrm{CaCO}_{3}$ a: 1,$23 ; 2,52$ e $3,80 \mathrm{t} \mathrm{ha}^{-1}$. Para o calcário, as doses empregadas foram 1,92; 3,92 e $5,93 \mathrm{t} \mathrm{ha}^{-1} \mathrm{e}$, para a escória de siderurgia, foram aplicadas 3,00; 6,12 e 9,27 t ha $a^{-1}$.

Nos tratamentos que receberam calcário, aplicaram-se os micronutrientes $\mathrm{Cu}, \mathrm{Zn}$ e $\mathrm{B}$ nas doses de 5,$91 ; 8,63$ e $3,28 \mathrm{~kg} \mathrm{ha}^{-1}$, quando o $\mathrm{V}$ era igual a $50 \%$ e, assim, proporcionalmente para o $\mathrm{V}$ igual a 75 e $100 \%$. Este procedimento teve por objetivo equilibrar o teor desses micronutrientes nos tratamentos com calcário, uma vez que a escória apresenta em sua composição tais elementos. Como fontes de micronutrientes, usaramse o sulfato de cobre, sulfato de zinco e o ácido bórico.

Durante o preparo do solo, aplicaram-se a escória de siderurgia e o calcário, manualmente, obedecendo à seguinte seqüência: metade aplicado a lanço, em área total, antes da aração (com aivecas) e a outra metade também aplicado a lanço, em área total, após a aração, mas antes da gradagem (grade aradora $14 \times 32$ "), procurando incorporar na camada de $0-20 \mathrm{~cm}$ de profundidade. Posteriormente, realizou-se o plantio da cana-de-açúcar em 2 de janeiro de 1998, variedade SP80-1842, deixando cerca de 15 gemas por metro de sulco, de modo que cada parcela ficou constituída por 6 linhas espaçadas de 1,3 metros e com 7,5 metros de comprimento, totalizando $58,5 \mathrm{~m}^{2}$ de área total. A bordadura entre parcelas e blocos foi de 2,0 e 2,6 metros, respectivamente. A área útil da parcela ficou constituída pelas quatro linhas centrais, perfazendo $39 \mathrm{~m}^{2}$.

Como adubação básica no plantio aplicaram-se, em todos tratamentos, $1300 \mathrm{~kg} \mathrm{ha}^{-1}$ da fórmula 4-14-8. $\mathrm{Na}$ mesma ocasião, foram aplicados $30 \mathrm{~kg} \mathrm{ha}^{-1} \mathrm{de}$ heptacloro, para o controle de pragas, distribuídos em todas as parcelas, no sulco de plantio. Em cobertura, foram utilizados $60 \mathrm{~kg} \mathrm{ha}^{-1}$ de $\mathrm{N}$ na forma de uréia e 60 $\mathrm{kg} \mathrm{ha}^{-1}$ de $\mathrm{K}_{2} \mathrm{O}$ na forma de cloreto de potássio, incorporados a $5 \mathrm{~cm}$ de profundidade, aos 42 dias após o plantio. Na cana-soca, foram aplicados $100 \mathrm{~kg} \mathrm{ha}^{-1} \mathrm{de}$ $\mathrm{N}$ e $150 \mathrm{~kg} \mathrm{ha}^{-1}$ de $\mathrm{K}_{2} \mathrm{O}$, aos 30 dias após a emergência dos brotos, incorporados em sulco raso a $40 \mathrm{~cm}$ da linha plantada e a $5 \mathrm{~cm}$ de profundidade. Para o controle de plantas daninhas, utilizou-se o método químico na canaplanta e o mecânico na cana-soca.

O estado nutricional da cana-planta e da canasoca foi avaliado aos 4 meses, através de amostragens da folha +3 (Gallo et al., 1968) e, posterior determinação das concentrações de macronutrientes. A colheita da cana sem a queima da palha realizou-se aos 345 dias após a emergência dos brotos, utilizando-se dinamômetro para pesagens das parcelas. Em cada 
parcela foram escolhidas ao acaso vinte colmos, apenas na cana-soca, onde a parte áerea das plantas, foi separada em folhas e colmos, obtendo-se a massa verde. Amostras homogêneas das folhas e dos colmos foram secas em estufa com circulação forçada de ar por 72 horas, para a obtenção do teor de umidade da massa vegetal. Determinou-se a matéria seca e, em seguida, foram analisados $\mathrm{N}, \mathrm{P}, \mathrm{K}, \mathrm{Ca}, \mathrm{Mg}$ e $\mathrm{S}$ nos tecidos vegetais. $\mathrm{O}$ nutriente acumulado referiu-se aos nutrientes contidos na parte aérea total da planta enquanto que os nutrientes exportados reporta-se apenas para aqueles contidos nos colmos. Portanto, para o cálculo dos nutrientes acumulados e exportados na parte aérea da cana-de-açúcar foram consideradas as concentrações dos nutrientes nas folhas totais+colmos e nos colmos respectivamente, multiplicado pela sua respectiva matéria seca.

O nitrogênio foi determinado por digestão sulfúrica e destilação e os demais nutrientes, por digestão nitroperclórica, sendo o $\mathrm{P}$ determinado por colorimetria, Ca e Mg por espectrometria de absorção atômica e K por fotometria de chama, segundo Sarruge \& Haag (1974).

A análise de variância seguiu a recomendação de Gomes (1985). Os resultados foram também submetidos à análise de regressão.

\section{RESULTADOS E DISCUSSÃO}

Não houve diferença entre os tratamentos, para os teores de macronutrientes no tecido foliar da canaplanta, coletados aos 120 dias após a emergência do broto (Tabela 1). Os resultados foram semelhantes àqueles obtidos por Gurgel (1979), que estudou o efeito do silicato de cálcio e do calcário nos teores foliares dos macronutrientes na cana-de-açúcar. Os valores dos teores de nutrientes nas folhas obtidos neste experimento situamse na faixa classificada como média e adequada para cultura, de acordo com Malavolta (1992).

Os teores de macronutrientes foliares na canasoca também não apresentaram diferença significativa entre os tratamentos (Tabela 2). Gavioli et al. (1992) também não constataram efeitos significativos da aplicação de calcário e de gesso nos teores foliares de $\mathrm{Mg}, \mathrm{S}, \mathrm{K}$ e $\mathrm{Ca}$, quando amostraram as folhas $+3 \mathrm{e}+4$ da cana-soca. No entanto, os valores encontrados para a cana-soca são próximos aos citados na literatura para folhas de plantas normais, considerado como nível médio ou adequado por Malavolta (1992).

As produtividades da cana-planta e da cana-soca apresentaram incremento quadrático, tanto pela aplicação do calcário como da escória de siderurgia (Figura 1).

Tendo em vista o efeito positivo dos materiais corretivos na produtividade da cana-de-açúcar, era de se esperar diferenças no estado nutricional das plantas através da análise foliar nas diferentes doses de corretivo. Existem duas hipóteses que podem explicar o ocorrido. A primeira refere-se ao efeito diluição, ou seja a concentração dos nutrientes é diluída com maior crescimento da planta, fato que é amplamente relatado na literatura (Jarrell \& Beverly, 1981). Embora não se disponha de resultados quantitativos, notou-se que o crescimento da cana-de-açúcar foi relativamente semelhante nas diversas parcelas dos tratamentos, portanto, esta hipótese é pouco provável de ter acorrido. A segunda hipótese, mais provável, refere-se ao tipo de folha amostrada $(+3)$, uma vez que existem outras recomendações como a folha 1 , que é a mais utilizada nas áreas de produção de cana-de-açúcar em nível

Tabela 1 - Valores médios de macronutrientes na folha da cana-planta aos 120 dias após a emergência do broto, em função da aplicação do calcário e da escória de siderurgia na safra 98/99.

\begin{tabular}{|c|c|c|c|c|c|c|}
\hline Corretivo (C) & $\mathrm{N}$ & $\mathrm{P}$ & $\mathrm{K}$ & $\mathrm{Ca}$ & $\mathrm{Mg}$ & $\mathrm{s}$ \\
\hline & -ב---- & 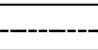 & $-----g$ & & & --.-- \\
\hline Calcário & 16,5 & 2,1 & 10,8 & 7,0 & 2,5 & 1,5 \\
\hline Escória & 16,2 & 2,0 & 10,8 & 7,5 & 2,3 & 1,5 \\
\hline $\mathrm{F}^{1}$ & $0,63^{\text {ns }}$ & $0,75^{\text {ns }}$ & $0,04^{\text {ns }}$ & $2,79^{\text {ns }}$ & $1,12^{\text {ns }}$ & $0,62^{\text {ns }}$ \\
\hline \multicolumn{7}{|c|}{ Dose equivalente $\mathrm{CaCO}_{3}$ (D) } \\
\hline \multicolumn{7}{|c|}{$\mathrm{t} \mathrm{ha}^{-1}$} \\
\hline 0 & 16,1 & 2,0 & 10,6 & 7,0 & 2,6 & 1,5 \\
\hline 1,23 & 16,2 & 2,0 & 10,9 & 7,4 & 2,3 & 1,5 \\
\hline 2,52 & 16,4 & 2,0 & 10,8 & 7,3 & 2,3 & 1,5 \\
\hline 3,80 & 16,8 & 2,1 & 11,0 & 7,3 & 2,3 & 1,5 \\
\hline $\mathrm{F}$ & $0,55^{\text {ns }}$ & $0,56^{\text {ns }}$ & $0,16^{\text {ns }}$ & $0,29^{\text {ns }}$ & $0,42^{\text {ns }}$ & $0,34^{\text {ns }}$ \\
\hline \multicolumn{7}{|l|}{$C \times D$} \\
\hline $\mathrm{F}$ & $0,46^{\text {ns }}$ & $0,94^{\text {ns }}$ & $0,33^{\text {ns }}$ & $0,26^{\text {ns }}$ & $0,75^{\text {ns }}$ & $0,24^{\text {ns }}$ \\
\hline Média & 16,4 & 2,0 & 10,8 & 7,2 & 2,4 & 1,5 \\
\hline CV (\%) & 7,6 & 3,8 & 10,6 & 12,3 & 25,3 & 7,1 \\
\hline
\end{tabular}

${ }^{1}$ não significativo $(P>0,05)$ pelo teste $F$. 
mundial segundo Orlando Filho \& Zambello (1983); entretanto, no Havaí, utilizam-se as folhas $+3,+4,+5$ e +6 (o ponteiro é considerado como folha +1 ) (Clements, 1959) e, em Porto Rico, as folhas $+4,+5$ e +6 (Samuels et al.,1960). Acrescenta-se a isto, o fato de que a amostragem das folhas das plantas podem ter sido realizada precocemente, aos 4 meses de idade, de forma que pode ter interferido nos resultados. Pode-se observar, assim, divergência quanto a parte da planta à ser amostrado. Sabendo-se que o tipo de folha define a sua idade que, por sua vez, constitui uma fonte de variação importante, isto pode dificultar as interpretações do estado nutricional da planta.

A semelhança de resultados entre a escória de siderurgia e o calcário, quanto aos teores foliares de macronutrientes da cana-de-açúcar, também foi constatada por Prado \& Fernandes (2000), em condições de casa de vegetação, tanto na cana-planta como na cana-soca.
Quanto ao acúmulo de macronutrientes pela parte aérea da cana-soca, não houve diferença entre os materiais corretivos no acúmulo de macronutrientes pela cana-soca. No entanto, houve diferença significativa para o efeito de doses dos diferentes materiais corretivos (Tabela 3) de forma que este efeito apresentou um comportamento quadrático nos nutrientes acumulados pela cana-de-açúcar (Figura 2a). Este resultado era esperado, uma vez que o cálculo dos nutrientes acumulados pela parte aérea está relacionado com a produção de colmos e de folhas e as doses destes corretivos incrementaram significativamente a produção de colmos da planta (Figura 1). A ausência de interação entre os materiais corretivos e as doses indica que, independentemente do material utilizado, houve alteração no acúmulo dos macronutrientes pela planta.

A resposta positiva da cana-de-açúcar à aplicação de materiais corretivos é bem conhecida, em

Tabela 2 - Valores médios de macronutrientes na folha da cana-soca aos 120 dias após a emergência do broto, em função da aplicação do calcário e da escória de siderurgia na safra 99/00.

\begin{tabular}{|c|c|c|c|c|c|c|}
\hline Corretivo $(\mathrm{C})$ & $\mathrm{N}$ & $\mathrm{P}$ & $\mathrm{K}$ & $\mathrm{Ca}$ & $\mathrm{Mg}$ & $S$ \\
\hline & ----------_. & ------- & ---- g & - & --------- & ---------- \\
\hline Calcário & 16,8 & 1,6 & 11,7 & 5,6 & 2,8 & 1,4 \\
\hline Escória & 16,7 & 1,6 & 11,7 & 5,8 & 2,8 & 1,5 \\
\hline $\mathrm{F}^{1}$ & $0,25^{\text {ns }}$ & $0,32^{\text {ns }}$ & $0,01^{\text {ns }}$ & $0,47^{\mathrm{ns}}$ & $0,13^{\text {ns }}$ & $0,87^{\text {ns }}$ \\
\hline \multicolumn{7}{|c|}{ Dose equivalente $\mathrm{CaCO}_{3}(\mathrm{D})$} \\
\hline \multicolumn{7}{|c|}{$\mathrm{t} \mathrm{ha}^{-1}$} \\
\hline 0 & 16,4 & 1,6 & 11,9 & 5,4 & 2,8 & 1,4 \\
\hline 1,23 & 17,1 & 1,6 & 11,1 & 5,5 & 2,8 & 1,5 \\
\hline 2,52 & 17,1 & 1,6 & 11,4 & 5,7 & 3,0 & 1,4 \\
\hline 3,80 & 16,5 & 1,6 & 12,5 & 6,2 & 2,6 & 1,4 \\
\hline $\mathrm{F}$ & $1,89^{\text {ns }}$ & $1,76^{\text {ns }}$ & $0,53^{\text {ns }}$ & $1,61^{\text {ns }}$ & $1,20^{\text {ns }}$ & $0,14^{\mathrm{ns}}$ \\
\hline \multicolumn{7}{|l|}{$C \times D$} \\
\hline $\mathrm{F}$ & $0,69^{\text {ns }}$ & $2,03^{\text {ns }}$ & $0,10^{\text {ns }}$ & $1,08^{\mathrm{ns}}$ & $6,24^{\mathrm{ns}}$ & $0,23^{\text {ns }}$ \\
\hline Média & 16,8 & 1,6 & 11,7 & 5,7 & 2,8 & 1,4 \\
\hline CV (\%) & 4,4 & 4,5 & 19,5 & 12,7 & 16,2 & 10,5 \\
\hline
\end{tabular}

${ }^{1}$ não significativo $(\mathrm{P}>0,05)$ pelo teste $\mathrm{F}$.
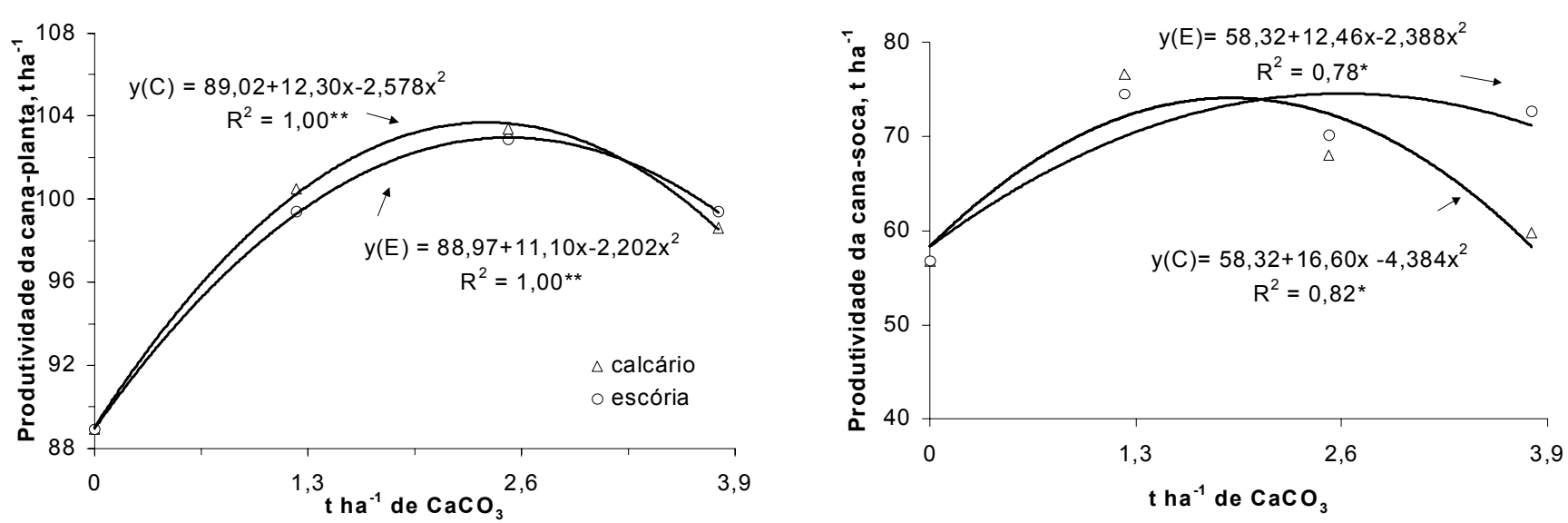

Figura 1 - Efeito da escória de siderurgia (E) e do calcário (C) na produtividade da cana-plante e da cana-soca (Média de quatro repetições).

*** - Resultado significativo $(P<0,01)$ e $(P<0,05)$. 
função da melhoria do ambiente radicular, uma vez que o solo utilizado era ácido, e a calagem, promove a neutralização da acidez do solo, aumentando a disponibilidade dos macronutrientes e, ainda, possibilitando a proliferação intensa das raízes, com reflexos positivos no crescimento da planta.

Como a produtividade de colmos mostra-se dependente do acúmulo de macronutrientes na parte aérea da cana-de-açúcar, independentemente do material corretivo utilizado, o que proporciona uma nutrição adequada à planta. Fato semelhante foi constatado por Anderson (1991), em área de cana-deaçúcar que recebeu a aplicação de escória de siderurgia. $\mathrm{O}$ autor observou que, quando o fornecimento dos macronutrientes não é limitado, o acúmulo desses elementos por unidade de área aumenta a produção de biomassa da planta.

O acúmulo médio pela parte aérea da cana-soca de N, P, K, Ca, Mg e S atingiu 150,0; 5,0; 104,9; 43,8; 21,9 e $5,4 \mathrm{~kg} \mathrm{ha}^{-1}$ respectivamente. Portanto, a ordem de extração de macronutrientes pela cana-soca foi: $\mathrm{N}>\mathrm{K}>\mathrm{Ca}>\mathrm{Mg}>\mathrm{S}>\mathrm{P}$. Estes resultados foram semelhantes aos obtidos por Orlando Filho et al. (1980), diferindo apenas para o $\mathrm{K}$, que foi o nutriente que a cana-soca (variedade CB 4176) mais extraiu naquele trabalho. Korndörfer et al. (1989), trabalhando com cana-de-açúcar (variedade SP71-1406) em ensaio de adubação fosfatada, obteveram acúmulo de 10,3 a $14,4 \mathrm{~kg} \mathrm{ha}^{-1}$ de $\mathrm{P}$ e 38,9 a $46,4 \mathrm{~kg} \mathrm{ha}^{-1}$ de $\mathrm{Ca}$, isto em plantas com 7 meses de idade. Nesta mesma variedade, Ferreira et al. (1989) obtiveram acúmulo de $\mathrm{P}$ de 11,0 a $17,9 \mathrm{~kg} \mathrm{ha}^{-1} \mathrm{e}$ de $S$ de 9,8 a $15,2 \mathrm{~kg} \mathrm{ha}^{-1}$, em plantas com 16 meses de idade. Portanto pode-se observar que a variação dos nutrientes acumulados, ocorre com a idade da planta. $E$ isto, associado com variedades distintas levam também a valores diferentes de nutrientes acumulados, o que dificulta a comparação dos resultados do presente trabalho com a literatura.

Da mesma forma como ocorreu com o acúmulo dos macronutrientes pela cana-soca, os materiais corretivos tiveram comportamento semelhante e, nas doses, afetaram significativamente a exportação dos macronutrientes (Tabela 4). Este efeito das doses dos materiais corretivos teve um comportamento quadrático nos nutrientes exportados pela cana-de-açúcar (Figura $2 b)$. O incremento da exportação de nutrientes em função das doses de corretivos era esperado, uma vez que aplicação dos materiais corretivos aumentaram a produtividade da cana-de-açúcar (Figura 1) e assim o cálculo dos nutrientes exportados pela parte aérea está relacionado com a produção de colmos.

A dose equivalente a $\mathrm{CaCO}_{3} 1,23 \mathrm{tha}^{-1}$ dos materiais corretivos foi, em valor absoluto, maior que as demais doses no aumento dos nutrientes acumulados e exportados (Tabela 3 e 4), pela cana-de-açúcar. Isto foi causado não só pelo aumento da produção, mas principalmente pela elevação das concentração dos nutrientes na matéria seca neste tratamento (dados não apresentados), com exceção dada ao $\mathrm{P}$ e $\mathrm{Mg}$ nos nutrientes acumulados e $\mathrm{Mg}$ nos nutrientes exportados.

As maiores extrações foram de $\mathrm{N}$ e $\mathrm{K}$, o que segundo Malavolta (1992), justifica a aplicação concentrada desses dois nutrientes na adubação das soqueiras da cana-de-açúcar.

Considerando que a produtividade média da cana-soca está entre 60 e $80 \mathrm{t} \mathrm{ha}^{-1}$ faixa semelhante à obtida neste experimento, tem-se uma extração líquida de N, P, K do solo de 87,$5 ; 4,1$ e $53,6 \mathrm{~kg} \mathrm{ha}^{-1}$ respectivamente. Neste cálculo, os nutrientes das folhas e raízes não são computados como exportados, já que

Tabela 3 - Valores médios de macronutrientes acumulados por área na parte aérea da cana-soca aos 345 dias após a emergência do broto em função da aplicação do calcário e da escória de siderurgia na safra 99/00.

\begin{tabular}{|c|c|c|c|c|c|c|}
\hline Corretivo (C) & $\mathrm{N}$ & $\mathrm{P}$ & $\mathrm{K}$ & $\mathrm{Ca}$ & $\mathrm{Mg}$ & $\mathrm{S}$ \\
\hline & & & ----- g & & & ------- \\
\hline Calcário & 147,4 & 5,0 & 106,1 & 43,1 & 21,8 & 5,5 \\
\hline Escória & 152,6 & 5,1 & 103,7 & 44,5 & 22,0 & 5,3 \\
\hline $\mathrm{F}^{1}$ & $1,05^{\mathrm{ns}}$ & $0,90^{\text {ns }}$ & $0,30^{\text {ns }}$ & $1,30^{\text {ns }}$ & $0,03^{\text {ns }}$ & $0,60^{\text {ns }}$ \\
\hline \multicolumn{7}{|c|}{ Dose equivalente $\mathrm{CaCO}_{3}(\mathrm{D})$} \\
\hline \multicolumn{7}{|c|}{$\mathrm{t} \mathrm{ha}^{-1}$} \\
\hline 0 & 129,0 & 4,1 & 75,3 & 34,2 & 18,7 & 4,5 \\
\hline 1,23 & 175,5 & 5,2 & 132,1 & 53,7 & 24,3 & 6,7 \\
\hline 2,52 & 148,8 & 5,9 & 105,3 & 45,3 & 24,7 & 5,4 \\
\hline 3,80 & 146,6 & 4,9 & 106,9 & 41,9 & 19,8 & 5,1 \\
\hline $\mathrm{F}$ & $14,23^{\star *}$ & $12,71^{\text {** }}$ & $24,00^{* *}$ & $42,10^{* *}$ & $5,94^{\star *}$ & $23,20^{* *}$ \\
\hline \multicolumn{7}{|l|}{$C \times D$} \\
\hline $\mathrm{F}$ & $0,60^{\text {ns }}$ & $0,70^{\text {ns }}$ & $0,14^{\mathrm{ns}}$ & $1,23^{\text {ns }}$ & $0,26^{\mathrm{ns}}$ & $1,41^{\mathrm{ns}}$ \\
\hline Média & 150,0 & 5,0 & 104,9 & 43,8 & 21,9 & 5,4 \\
\hline CV (\%) & 9,6 & 11,8 & 12,8 & 8,0 & 16,3 & 9,7 \\
\hline
\end{tabular}

${ }^{1} \mathrm{~ns} ;{ }^{* *}$ : não significativo $(\mathrm{P}>0,05)$ e significativo $(\mathrm{P}<0,01)$ pelo teste $\mathrm{F}$. 
Tabela 4 - Valores médios macronutrientes exportados por área da cana-soca aos 345 dias após a emergência do broto em função da aplicação do calcário e da escória de siderurgia na safra 99/00.

\begin{tabular}{|c|c|c|c|c|c|c|}
\hline Corretivo $(\mathrm{C})$ & $\mathrm{N}$ & $P$ & $\mathrm{~K}$ & $\mathrm{Ca}$ & $\mathrm{Mg}$ & S \\
\hline & \multicolumn{6}{|c|}{ - } \\
\hline Calcário & 86,2 & 4,0 & 53,8 & 26,5 & 10,8 & 4,6 \\
\hline Escória & 88,8 & 4,1 & 53,4 & 27,6 & 11,0 & 4,4 \\
\hline $\mathrm{F}^{1}$ & $0,60^{\text {ns }}$ & $0,22^{\text {ns }}$ & $0,20^{\text {ns }}$ & $1,24^{\mathrm{ns}}$ & $0,20^{\text {ns }}$ & $1,10^{\text {ns }}$ \\
\hline \multicolumn{7}{|c|}{ Dose equivalente $\mathrm{CaCO}_{3}(\mathrm{D})$} \\
\hline \multicolumn{7}{|c|}{$\mathrm{t} \mathrm{ha}^{-1}$} \\
\hline 0 & 74,2 & 3,2 & 27,2 & 19,8 & 8,5 & 3,7 \\
\hline 1,23 & 101,2 & 4,3 & 66,6 & 33,4 & 10,9 & 5,5 \\
\hline 2,52 & 85,7 & 4,7 & 58,7 & 28,3 & 14,1 & 4,5 \\
\hline 3,80 & 89,0 & 4,1 & 61,8 & 26,5 & 10,2 & 4,4 \\
\hline $\mathrm{F}$ & $10,60^{\star *}$ & $8,90^{* *}$ & $55,49^{* *}$ & $34,22^{* \star}$ & $4,60^{*}$ & $20,50^{\star *}$ \\
\hline \multicolumn{7}{|l|}{$C \times D$} \\
\hline $\mathrm{F}$ & $0,60^{\text {ns }}$ & $0,47^{\text {ns }}$ & $0,42^{\text {ns }}$ & $1,52^{\mathrm{rs}}$ & $0,18^{\mathrm{ns}}$ & $1,50^{\text {ns }}$ \\
\hline Média & 87,5 & 4,1 & 53,6 & 27,0 & 10,9 & 4,5 \\
\hline CV $(\%)$ & 11,0 & 14,9 & 12,7 & 10,1 & 28,3 & 10,5 \\
\hline
\end{tabular}

${ }^{1}$ ns; **; * : não significativo $(P>0,05)$ e significativo $(P<0,01)$ e $(P<0,05)$ pelo teste $F$.
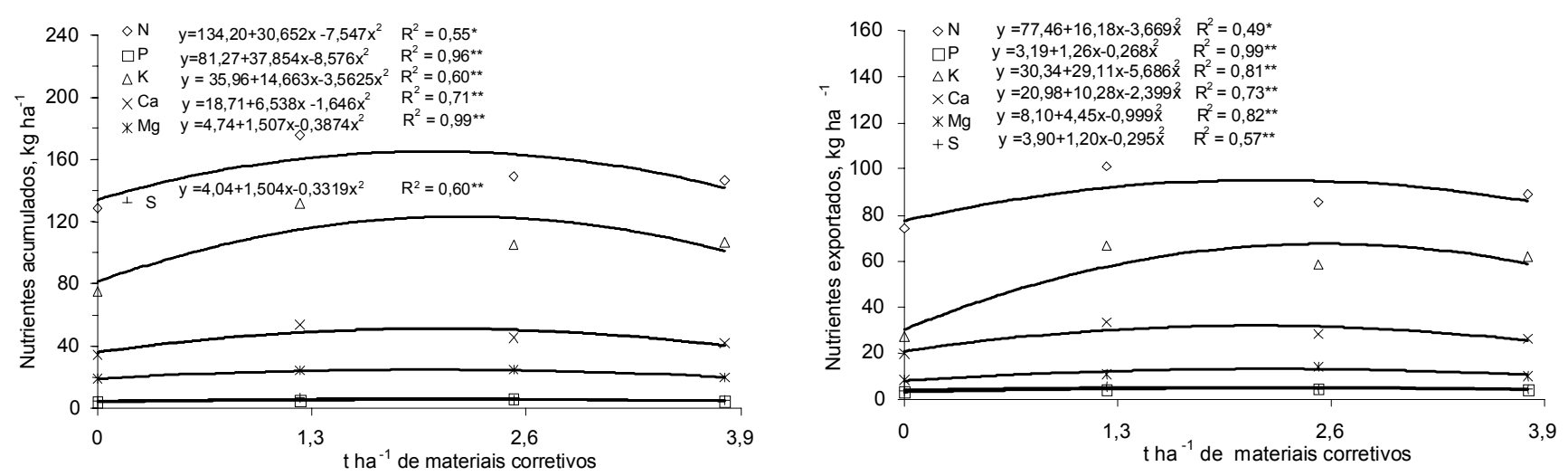

Figura 2 - Efeito dos materiais corretivos (média da escória de siderurgia e do calcário) nos nutrientes acumulados (a) e exportados (b) na parte aérea da cana-soca (Média de quatro repetições).

**;*- Resultado significativo $(P<0,01)$ e $(P<0,05)$ respectivamente.

permanecem no solo como resíduo vegetal. No entanto, se a taxa de fertilização segue a recomendação baseada na fertilidade do solo e uma produtividade esperada (60$\left.80 \mathrm{t} \mathrm{ha}^{-1}\right)$ semelhante à deste experimento, tem-se para $\mathrm{N}, \mathrm{P}, \mathrm{K}$, respectivamente: $80 ; 30$ e $110 \mathrm{~kg} \mathrm{ha}^{-1}$ (Raij et al., 1996). Nestas circunstâncias, o solo estaria anualmente com déficit de $\mathrm{N}$ de $7,5 \mathrm{~kg} \mathrm{ha}^{-1}$, ao passo que o $\mathrm{P}$ e K teriam superávit de 25,9 e $56,4 \mathrm{~kg} \mathrm{ha}^{-1}$, respectivamente. Para o K, estes valores de exportação correspondem, em média (exceto testemunha), a $0,95 \mathrm{~kg}$ $\mathrm{t}^{-1}$ de colmo industrial, valor inferior ao encontrado por Malavolta (1982), que obteve $1,10 \mathrm{~kg} \mathrm{t}^{-1}$ de colmo.

O superávit da fertilização potássica também foi relatado por Sampaio \& Salcedo (1991) em área cultivada com cana-de-açúcar (variedade Co 997), que obtiveram uma exportação de $42 \mathrm{~kg} \mathrm{ha}^{-1}$ de $\mathrm{K}$ (média de 3 cortes), valor inferior ao do presente ensaio (53,6 kg $\left.\mathrm{ha}^{-1} \mathrm{de} \mathrm{K}\right)$. Os autores acrescentam que parte significativa desse superávit de $\mathrm{K}$ deve ficar no solo, pois as perdas em área de cana-de-açúcar são diminutas, uma vez que encontraram perdas anuais inferiores a 7 $\mathrm{kg} \mathrm{ha}^{-1}$ de $\mathrm{K}$ (abaixo de $1 \mathrm{~m}$ de profundidade).

\section{CONCLUSÕES}

Os materiais corretivos e as doses não afetaram o teor de macronutrientes da cana-de-açúcar. Houve maior acúmulo e exportação de macronutrientes de acordo com as doses de ambos corretivos.

A escória de siderurgia foi semelhante ao calcário na nutrição da cana-de-açúcar, quanto aos macronutrientes.

\section{AGRADECIMENTO}

À FAPESP pelo financiamento da pesquisa (Proc.97/05888-5). 


\section{REFERÊNCIAS BIBLIOGRÁFICAS}

ANDERSON, D.L. Soil and leaf nutrient interactions following application of calcium silicate slag to sugarcane. Fertilizer Research, v.30, p.9-18, 1991.

ASSOCIAÇÃO NACIONAL PARA DIFUSÃO DE ADUBOS E CORRETIVOS AGRÍCOLAS. Anuário estatístico do setor de fertilizantes - 1999. São Paulo: ANDA, 1987-2000.156p.

BATAGLIA, O.C.; RAIJ, B. van. Eficiência de extratores na determinação de boro em solos. Revista Brasileira de Ciência do Solo, v.14, p.25-31,1990.

CARVALHO, L.C.C. Cenário sucroalcooleiro. STAB Açúcar, Álcool e Subprodutos, v.17, p.12-13, 1999.

CATANI, R.A.; ARRUDA, H.C.; PELEGRINO, D.; BERGAMIN FILHO, H. A absorção de nitrogênio, fósforo, potássio, cálcio, magnésio e enxofre pela cana-de-açúcar Co419 e o seu crescimento em função da idade. Anais da ESALQ, v.16, p.167-190, 1957.

CLEMENTS, H.F. Sugarcane nutrition and culture. Lucknow: Indian Institute Research, 1959. 89p.

FERREIRA, E.S.; CACERES, N.T.; KORNDÖRFER, G.H.; MARTINS, J.; MATHIESEN, L.A. Uso de multifosfato magnesiano na adubação de plantio da cana-de-açúcar. Boletim Técnico Copersucar, v.46/49, p.6-11,1989.

GALLO, J.R.; HIROCE, R.; ALVAREZ, R. Levantamento do estado nutricional de canaviais de São Paulo pela análise foliar. Bragantia, v.27, p.365-82, 1968.

GAVIOLI, E.A.; CASAGRANDE, A.A.; MUTTON, M.A.; VITTI, G.C.; PARANHOS, S.B.; CAMPANHÃO, J. Aplicação de calcário, gesso e mistura calcário/gesso em soca de canade-açúcar. I. Efeitos na planta. STAB Açúcar, Álcool e Subprodutos, v.10, p.17-24, 1992.

GOMES, F.P. Curso de estatística experimental. 11.ed. São Paulo: Nobel, 1985. 466p.

GURGEL, M.N.A. Efeitos do silicato de cálcio e sua interação com o fósforo no estado nutricional, produtividade e qualidade tecnológica da cana-de-açúcar. Piracicaba, 1979. 62p. Dissertação (Mestrado) - Escola Superior de Agricultura "Luiz de Queiroz", Universidade de São Paulo.

JARRELL, W.M.; BEVERLY, R.B. The dilution effect in plant nutrition studies. Advances in Agronomy, v.34, p.197-224, 1981.

KORNDÖRFER, G.H.; VIEIRA, G.G.; MARTINS, J.; MATHIESEN, L.A. Resposta da cana-planta à diferentes fontes de fósforo. Boletim Técnico Copersucar, v.45, p.31$37,1989$.

LINDSAY, W.L.; NORWELL, W.A. Development of a DTPA soil test for zinc, iron, manganese and copper. Soil Science Society of America Journal, v.42, p.421-428, 1978.

MALAVOLTA, E. ABC da análise de solo e folhas: amostragem, interpretação e sugestões de adubação. São Paulo: Agronômica Ceres, 1992. 124p.
MALAVOLTA, E. Potássio, magnésio e enxofre nos solos e culturas brasileiras. 3.ed. Piracicaba: Instituto da Potassa \& Fosfato; Instituto Internacional da Potassa, 1982. 162p.

NATIONAL INSTITUTE OF AGRO-ENVIRONMENTAL SCIENCES. Official methods of analysis of fertilizers. Tsukuba: Fundation Nohrin Kohsaikai, 1987. 124p.

ORLANDO FILHO, J.; HAAG, H.P.; ZAMBELLO JR., E. Crescimento e absorção de macronutrientes pela cana-deaçúcar, variedade CB 41-76, em função da idade, em solos do Estado de São Paulo. Boletim Técnico Planalsucar, v.2, p.1-128, 1980.

ORLANDO FILHO, J.; ZAMBELLO JÚNIOR, E. Diagnose foliar. In: ORLANDO FILHO, J. (Ed.) Nutrição e adubação da canade-açúcar no Brasil. Piracicaba: PLANALSUCAR, 1983. p.125-152.

PRADO, R.M. Resposta da cultura da cana-de-açúcar à aplicação de escória silicatada como corretivo de acidez do solo. Ilha Solteira, 2000. 97p. Dissertação (Mestrado) Faculdade de Engenharia de Ilha Solteira, Universidade Estadual Paulista "Júlio de Mesquita Filho".

PRADO, R.M.; FERNANDES, F.M. Eficiência da escória de siderurgia em Areia Quartzosa na nutrição e na produção de matéria seca de cana-de-açúcar cultivada em vaso. STAB Açúcar, Álcool e Subprodutos, v.18, p.36-39, 2000.

PRADO, R.M.; FERNANDES, F.M. Escória de siderurgia e calcário na correção da acidez do solo cultivado com canade-açúcar em vaso. Scientia Agricola, v.57, p.739-744, 2000.

QUAGGIO, J.A. A acidez e calagem em solos tropicais. Campinas: Instituto Agronômico, 2000. 111p.

RAIJ, B. van; CANTARELLA, H.; QUAGGIO, J.A.; FURLANI, A.M.C. Recomendações de adubação e calagem para o Estado de São Paulo. 2.ed. Campinas: Instituto Agronômico, 1996. 255p. (Boletim Técnico, 100).

RAIJ, B. van, QUAGGIO, J.A.; CANTARELLA, H. Análise química do solo para fins de fertilidade. Campinas: Fundação Cargill, 1987. 107p.

SAMPAIO, E.V.S.B.; SALCEDO, I.H. Dinâmica de nutrientes em cana-de-açúcar. V. Balanço de K em quatro ciclos de cultivo. Pesquisa Agropecuária Brasileira, v.26, p.1323-1335, 1991.

SAMUELS, G.; LANDRAU JR., P.; ALERS, S. Influence of height of cane and leaf stage at time of sampling on leaf nutrients contents. The Journal of Agriculture of the University of Puerto Rico, v.44, p.11-15, 1960.

SARRUGE, J.R.; HAAG, H.P. Análise química em plantas. Piracicaba: ESALQ, Departamento de Química. 1974.56p.

Recebido em 14.11.00 